OPEN ACCESS

Edited by:

Konstantinos Tziomalos,

Aristotle University of

Thessaloniki, Greece

Reviewed by:

Yusuf Taha Gullu,

Ondokuz Mayis University, Turkey

Yoshitaka Hashimoto,

Kyoto Prefectural University of

Medicine, Japan

${ }^{*}$ Correspondence:

Xin Yu

yuxin@bjmu.edu.cn

Jincai He

hjc@wmu.edu.cn

tThese authors have contributed equally to this work

Specialty section:

This article was submitted to Nutritional Immunology,

a section of the journal

Frontiers in Nutrition

Received: 07 January 2022 Accepted: 31 January 2022

Published: 22 February 2022

Citation:

Ren $W, W u J, W u Z$, Yang S, Jiang $X$

$X u M, W u B$, Xie C, He J and YuX

(2022) Serum Uric Acid Levels at Admission Could Predict the Chronic Post-stroke Fatigue.

Front. Nutr. 9:850355.

doi: 10.3389/fnut.2022.850355

\section{Serum Uric Acid Levels at Admission Could Predict the Chronic Post-stroke Fatigue}

\author{
Wenwei Ren ${ }^{1 \dagger}$, Junxin $W^{1+}$, Zijing $W_{u^{1}}$, Shuang Yang ${ }^{1}$, Xiaofang Jiang ${ }^{2}$, Minjie $X u^{1}$, \\ Beilan $\mathrm{Wu}^{2}$, Caixia Xie ${ }^{1}$, Jincai $\mathrm{He}^{2 *}$ and $\mathrm{Xin} \mathrm{Yu}^{1,3,4,5 *}$ \\ ${ }^{1}$ School of Mental Health, Wenzhou Medical University, Wenzhou, China, ${ }^{2}$ Department of Neurology, The First Affiliated \\ Hospital of Wenzhou Medical University, Wenzhou, China, ${ }^{3}$ Peking University Institute of Mental Health (Sixth Hospital), \\ Beijing, China, ${ }^{4}$ National Clinical Research Center for Mental Disorders and Key Laboratory of Mental Health, Ministry of \\ Health, Peking University, Beijing, China, ${ }^{5}$ Beijing Municipal Key Laboratory for Translational Research on Diagnosis and \\ Treatment of Dementia, Beijing, China
}

Background: Post-stroke fatigue (PSF) is a frequent complication of stroke. Serum uric acid (SUA) is frequently thought to be a risk factor for stroke. This study aimed to investigate whether SUA also played a role in PSF.

Methods: Subjects with ischemic stroke were screened from The First Affiliated Hospital of Wenzhou Medical University between January 2020 and October 2020. Patients' fatigue symptoms were assessed by the Fatigue severity scale (FSS). To investigate the relationship between SUA and PSF, binary logistic regression analysis was conducted, with the confounders being controlled. SUA levels were divided into four layers (Q1 $\leq 245$ $\mu \mathrm{mol} / \mathrm{L} ;$ Q2 246-308 $\mu \mathrm{mol} / \mathrm{L} ;$ Q3 309-365 $\mu \mathrm{mol} / \mathrm{L} ;$ Q4 $\geq 366 \mu \mathrm{mol} / \mathrm{L})$ based on the quartiles.

Results: SUA levels were significantly higher in the PSF group (345.96 $\pm 73.78 \mu \mathrm{mol} / \mathrm{L})$ than the non-PSF group $(295.97 \pm 87.8 \mu \mathrm{mol} / \mathrm{L}, P<0.001)$. There were no differences in any other variables between these two groups. After adjusting the confounders, the risk of PSF in the Q4 layer ( $\geq 366 \mu \mathrm{mol} / \mathrm{L})$ was 6.05 times $(95 \% \mathrm{Cl} 1.79-20.43, P=0.004)$ higher than that in Q1 $(\leq 245 \mu \mathrm{mol} / \mathrm{L})$.

Conclusion: High SUA at admission was an independent risk factor for fatigue 1 year after stroke onset. High SUA ( $\geq 366 \mu \mathrm{mol} / \mathrm{L}$ ) during stroke deserves more attention, and active control of high SUA levels may be beneficial to reduce the incidence of PSF in the chronic stage following stroke.

Keywords: stroke, fatigue, uric acid, risk, association

\section{INTRODUCTION}

PSF is a common complication after stroke and predominantly presents lacking energy, excessive sleepiness, fatigability after activity, napping, or increased stress-induced sensitivity (1). According to previous studies, the incidence of PSF ranged from $25-85 \%$, with a pooled prevalence estimated at $50 \%$ (95\% CI: $43-57 \%)$ (2). More than half of patients with mild stroke who had little or no residual neurological deficits suffered from PSF (3). PSF was the second major barrier to the recovery of stroke survivors (4). Accumulating studies had observed that fatigue could lead to 
poorer quality of life, and higher rates of disability and mortality (5-10). Previous studies had demonstrated that fatigue and depressive symptoms were highly correlated $(5,11)$, and 34$49 \%$ of patients with fatigue were accompanied by depression symptoms $(12,13)$. It should be noted that fatigue also occurred in $47 \%$ of non-depressed stroke survivors (2). Previous studies on PSF often failed to exclude the confusion caused by depression (14-17). This study will focus on fatigue patients without depression symptoms, which can reduce the confounding effects caused by depression (11).

Uric acid is a metabolite of purine degradation, which can lead to kidney stones and gout (18). The biological functions of UA are bilateral. On one hand, it has been discovered that uric acid has an antioxidant property $(19,20)$, which contributes to nearly $50 \%$ of human plasma's antioxidant capacity (21). Accumulating studies had found its protective effect in different neurologic diseases, such as Parkinson's disease, amyotrophic lateral sclerosis, and multiple sclerosis (22-25). On the other hand, uric acid may also have pro-inflammatory effects on vascular cells and could generate radicals through the stimulation of NADPH oxidase (26-28).

Post-stroke fatigue could be classified as early and late fatigue, and early fatigue was defined as within 3 months post-stroke (acute stage) and late as more than 3 months post-stroke (chronic stage) $(29,30)$. In addition, previous studies had found that fatigue prevalence may decrease in the acute stage (1-3 months post-stroke), and then keep stable in the chronic stage (over 3 months) (31, 32). It should be noted that fatigue occurring in the acute stage following stroke was considered as a general non-specific response to the major disruptive event caused by stroke, while, fatigue in the chronic stage following stroke was considered to be a stroke-related sequel (33). A previous study observed that low SUA levels at admission were related to an increased risk of fatigue during the acute stage of stroke (17). As PSF occurred in the acute stage was considered to be a general non-specific response instead of a stroke-related sequel, the purpose of this study was to see if SUA at admission was also related to PSF in the chronic stage of stroke.

\section{METHODS}

\section{Participants}

Patients with acute ischemic stroke were screened between January 2020 and October 2020, from the First Affiliated Hospital of Wenzhou Medical University. Inclusion criteria were listed below: (1) age $\geq 18$ years old; (2) diagnosed with acute ischemic stroke, and confirmed by magnetic resonance imaging; Exclusion criteria were listed below: (1) with a history of psychiatric disorder; (2) with diseases related to fatigue including cancer, multiple sclerosis, Parkinson's disease, and systemic lupus erythematosus; (3) declined to participate; (4) Patient Health Questionnaire-9 (PHQ-9) score $\geq 5$; (5) data incomplete.

As was shown in Figure 1, 524 patients were screened, of which 351 were excluded and 173 patients were finally recruited.

The Ethics Committee of the First Affiliated Hospital of Wenzhou Medical University had approved this study. Due to the overall impact of COVID-19, all the participants provided verbal informed consent and finished the questionnaires by telephone.

\section{Data Collection}

The baseline characteristics were obtained from the electronic clinical records. General demographic information included

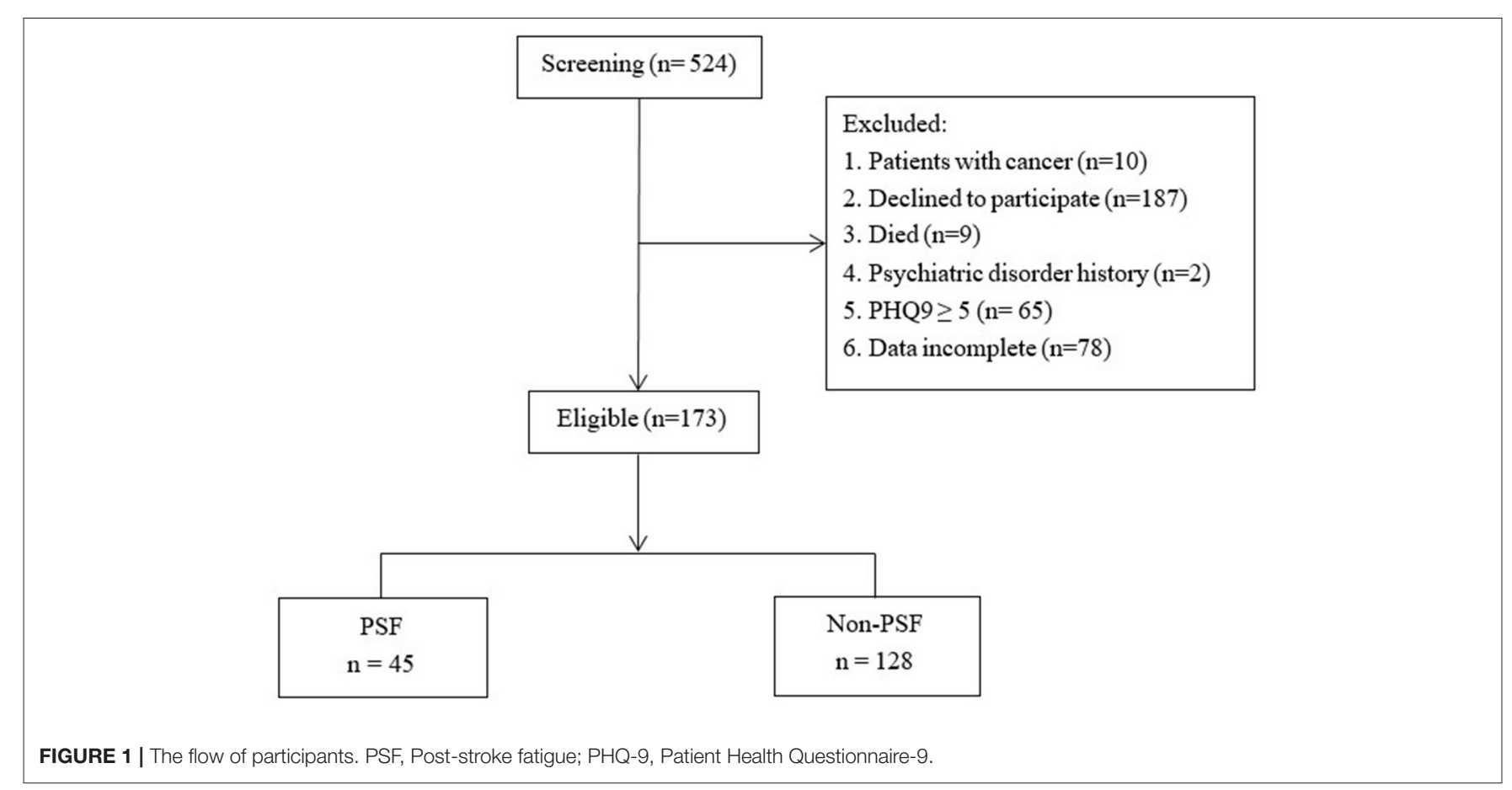


age, gender, smoking history, drinking history, and Body Mass Index (BMI). Comorbidity data included hypertension, diabetes, and atrial fibrillation. Clinical data included systolic and diastolic blood pressure, length of hospital stay, National Institutes of Health Stroke Scale (NIHSS) score, and stroke etiology (TOAST criteria). No patients had used anti-uric acid medication at admission. Blood samples were obtained in the morning, after $12 \mathrm{~h}$ of fasting. Laboratory data including SUA and creatinine were measured in the hospital biochemistry department. Functional outcomes were evaluated by telephone 1 -year post-stroke by the modified Rankin Scale (mRS) and the Barthel Index (BI).

\section{Clinical Assessments Depression}

Depression was assessed by the PHQ-9, a nine-item questionnaire for depression screening. Each item of the scale is scored from "0" (not at all) to " 3 " (nearly every day). Participants with the PHQ-9 score $\geq 5$ were considered to be depressed and were excluded in this study to eliminate the effects of depression on fatigue (34).

\section{Fatigue}

Fatigue was assessed by the Fatigue Severity Scale (FSS), a nineitem questionnaire for fatigue screening. Each item of the scale is scored from " 1 " (strongly disagree) to " 7 " (strongly agree), and a higher average score indicates a higher fatigue level. An average score of 4 or above is indicative of fatigue (35).

\section{Statistical Analysis}

Continuous data were displayed as mean \pm standard deviation (mean $\pm \mathrm{SD}$ ) or median (inter-quartile range) based on the distribution of the data, and Student's $t$-test or Mann-Whitney $\mathrm{U}$ test was adopted separately to analyze the differences between the PSF and non-PSF groups. Categorical variables were shown as frequencies or percentages, which were analyzed by the Chisquare test or the Fisher's exact test. Binary logistic regression analysis was used to explore the potential predictors of PSF, and the results were displayed by the forest plot. Except for the SUA, age, gender, creatinine, mRS, and stroke etiology (TOAST criteria) which can influence the SUA and fatigue levels were also included in the regression model, and SUA levels were divided into four layers (Q1 $\leq 245 \mu \mathrm{mol} / \mathrm{L}$; Q2 246-308 $\mu \mathrm{mol} / \mathrm{L}$; Q3 309$365 \mu \mathrm{mol} / \mathrm{L}$; Q $4 \geq 366 \mu \mathrm{mol} / \mathrm{L}$ ) based on the quartiles, with the Q1 being the reference.

SPSS 16.0 was used to conduct all the statistical analyses, and $P<0.05$ was suggestive of statistical significance.

\section{RESULTS}

\section{Characteristics Between the PSF and Non-PSF Groups}

Table 1 had demonstrated the demographic and clinical characteristics between the PSF and non-PSF groups. The SUA levels were significantly higher in the PSF group $(345.96 \pm 73.78$ $\mu \mathrm{mol} / \mathrm{L})$ than the non-PSF group $(295.97 \pm 87.80 \mu \mathrm{mol} / \mathrm{L}, P<$
0.001). There were no differences between the two groups in any other variables (all $P>0.05$ ).

\section{SUA and PSF}

The binary logistic regression analysis showed that patients in the Q4 layer showed a higher risk of PSF than those in Q1 (OR:5.47, 95\%CI: $1.80-16.60, P=0.003$ ). As was shown in Figure 2, after controlling the confounders, patients in the Q4 layer still had a 6.05-fold increased risk of PSF than those in Q1. The results remained unchanged when the SUA levels were taken as continuous variables in the model (OR:1.008, 95\% CI: 1.003-1.013, $P=0.003)$.

\section{DISCUSSION}

To our knowledge, this study is the first to investigate the relationship between SUA and PSF in the chronic stage following stroke. In this study, a high SUA level was a risk factor of fatigue 1 year after stroke onset. The prevalence of PSF was 6.05 times higher in the high SUA group $(\geq 366 \mu \mathrm{mol} / \mathrm{L})$ than in the low SUA group ( $\leq 245 \mu \mathrm{mol} / \mathrm{L})$.

The relationship between SUA and stroke had been widely studied. SUA was found to be an independent risk factor for ischemic stroke (36) and non-fatal stroke (37), furthermore, SUA could predict poor outcomes of stroke (38). A recent metaanalysis including 15 prospective studies has shown that higher SUA levels indicated a higher incidence of stroke and risk of mortality of stroke (39). In addition, high SUA levels were also associated with post-stroke cognitive impairment and poststroke depression (40-42). The relationship between SUA and PSF was rarely studied. A previous cross-sectional study by Shang et al. observed that a lower SUA level may indicate a higher risk of PSF during the acute stage of stroke (17), which was inconsistent with our study. Several reasons may explain this difference. On one hand, fatigue was assessed during the acute stage in the study by $\mathrm{Wu}$ et al. (17). While fatigue in this study was assessed 1 year after stroke (chronic stage). On the other hand, $82.6 \%$ of patients in the fatigue group had depression symptoms in the study by Shang et al. However, SUA was also found to be related to post-stroke depression (40). Therefore, in this study, patients with depression symptoms were excluded, which may reduce the confounding effects caused by depression to some extent. It was worth noting that another study in humans involving 54 healthy volunteers also found that increased SUA levels were associated with fatigue (43), which was consistent with our study. In addition, studies in animals found that fatigue after partial hepatectomy in rats was associated with increased hypoxanthine and UA levels (44). Besides, It was also observed in horses that plasma inosine Monophosphate concentration increased, ATP concentration decreased, and UA concentration significantly increased after a short period of high-intensity exercise (45). Given above, SUA may play an important role in fatigue. The mechanism underlying the SUA and fatigue remained unclear. It was inferred that systemic inflammatory response may play a significant role in the relationship between SUA and PSF. It had been studied that SUA was associated with inflammatory markers including TNF-alpha, IL-6, IL-1ra, IL-18, neutrophils count, 
TABLE 1 | Comparison of characteristics between the PSF and Non-PSF groups.

\begin{tabular}{|c|c|c|c|c|}
\hline Variables & $\begin{array}{l}\text { Non-PSF } \\
(n=128)\end{array}$ & $\begin{array}{c}\text { PSF } \\
(n=45)\end{array}$ & $\chi 2 / t / U$ & $P$-value \\
\hline Age, Mean \pm SD & $53.95 \pm 8.85$ & $54.67 \pm 7.82$ & -0.508 & 0.612 \\
\hline Gender(male), $n(\%)$ & $104(81.25)$ & $38(84.44)$ & 0.065 & 0.799 \\
\hline BMI, Mean \pm SD & $24.79 \pm 2.98$ & $24.7 \pm 2.86$ & 0.192 & 0.848 \\
\hline Hypertension, $n$ (\%) & 78 (60.94) & $29(64.44)$ & 0.057 & 0.812 \\
\hline Heart disease, $n(\%)$ & $5(3.91)$ & $2(4.44)$ & Fisher & 1 \\
\hline Diabetes, $n(\%)$ & $39(30.47)$ & $11(24.44)$ & 0.331 & 0.565 \\
\hline Atrial fibrillation, $n(\%)$ & $7(5.47)$ & $2(4.44)$ & Fisher & 1 \\
\hline Smoking, $n(\%)$ & 75 (58.59) & $21(46.67)$ & 1.465 & 0.226 \\
\hline Drinking, $n(\%)$ & $55(42.97)$ & $16(35.56)$ & 0.481 & 0.488 \\
\hline SBP $(\mathrm{mmHg})$, Mean \pm SD & $151.67 \pm 25.84$ & $157 \pm 23.41$ & -1.278 & 0.205 \\
\hline $\mathrm{DBP}(\mathrm{mmHg})$, Mean $\pm \mathrm{SD}$ & $90.39 \pm 16.57$ & $93.82 \pm 14.39$ & -1.321 & 0.19 \\
\hline Length of hospital stay, Median (IQR) & $8(7,10)$ & $7(6,9)$ & 3284.5 & 0.159 \\
\hline \multicolumn{5}{|l|}{ TOAST, $n$ (\%) } \\
\hline Large artery atherosclerosis & $66(51.56)$ & $29(64.44)$ & 1.742 & 0.187 \\
\hline Non-large artery atherosclerosis & $62(48.44)$ & $16(35.56)$ & & \\
\hline NIHSS, Median (IQR) & $1(0,2)$ & $1(0,2)$ & 2826.5 & 0.85 \\
\hline PHQ-9, Median (IQR) & $1(0,2)$ & $1(0,2)$ & 2835.5 & 0.874 \\
\hline mRS, Median (IQR) & $1(0,1)$ & $0(0,1)$ & 3230 & 0.186 \\
\hline Barthel Index, Median (IQR) & $100(100,100)$ & $100(100,100)$ & 2956.5 & 0.55 \\
\hline SUA, Mean \pm SD & $295.97 \pm 87.80$ & $345.96 \pm 73.78$ & -3.714 & $<0.001^{\star \star \star}$ \\
\hline
\end{tabular}

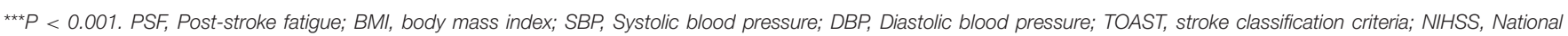

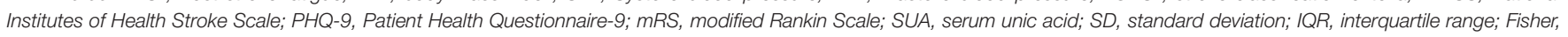
Fisher exact test.

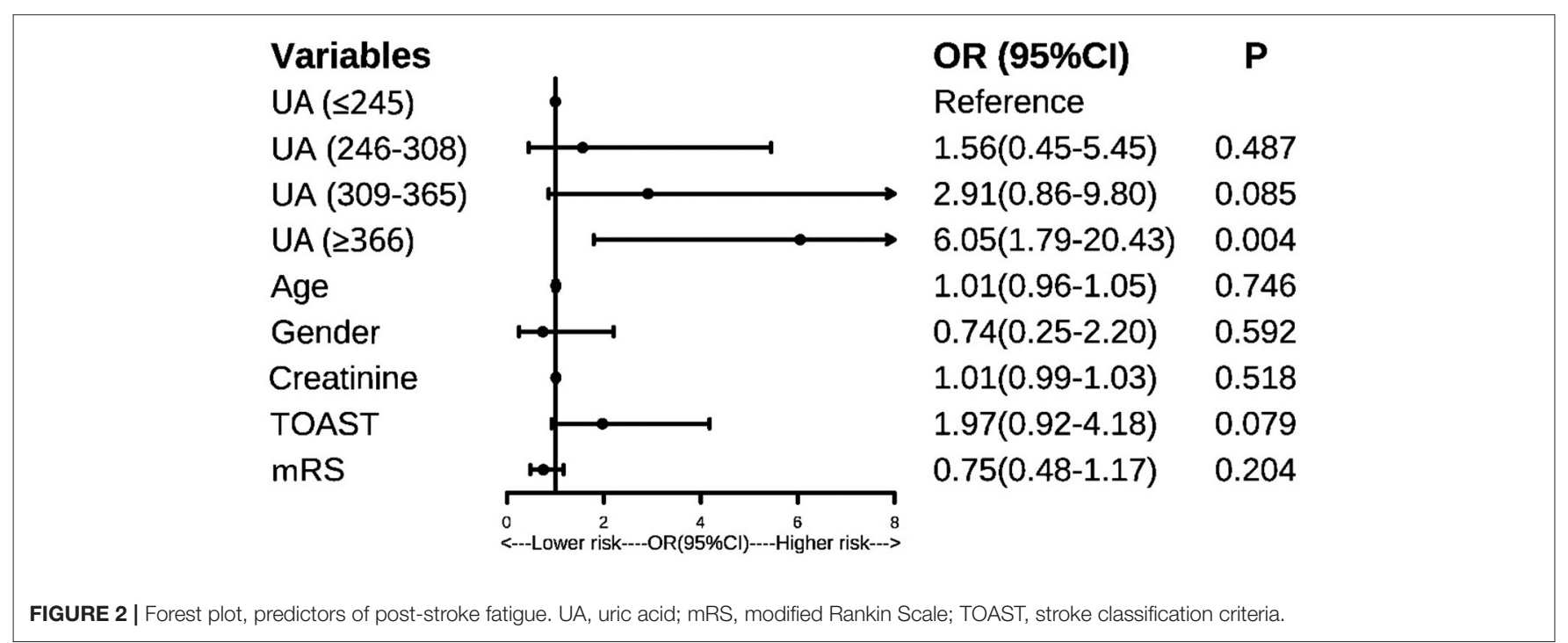

and C-reactive protein (CRP) (46). It was worth mentioning that IL-6, TNF-alpha, IL-1 $\beta$ were all significantly associated with fatigue (47-49). Besides, a study in patients with breast cancer found that CRP levels significantly decreased with the improvement of fatigue (50). Another study also found that PSF was associated with higher levels of CRP (51). Furthermore, a recent study found that UA could activate the pyrin domain containing 3 (NLRP3) inflammasome. After the formation of the NLRP3 inflammasome, NLRP3 inflammasome-dependent caspase-1 activation could stimulate macrophages to secrete interleukin-1 $\beta$ (IL-1 $\beta$ ) (28). It had been found that interleukin$1 \beta$ (IL-1 $\beta$ ) was positively correlated with the PSF at 6 months after stroke (52). Given above, systemic inflammation may play an important role between SUA and PSF (29).

The limitations of this study are listed as follows. 1. This study only measured SUA levels once at admission. As SUA levels may fluctuate over time, it is best to test SUA more times in the future; 2 . The sample size is relatively small, which should 
be further expanded in the future; 3 . Since it is a retrospective study, the causal relationship between SUA and PSF cannot be drawn. Future intervention studies are needed to further analyze the relationship between SUA and PSF.

\section{CONCLUSION}

High SUA level at admission was an independent risk factor for fatigue 1 year after stroke onset. Patients with high SUA levels at admission deserve more attention, and active control of SUA levels may be beneficial for reducing the incidence of PSF in the chronic stage following stroke.

\section{DATA AVAILABILITY STATEMENT}

The raw data supporting the conclusions of this article will be made available by the authors, without undue reservation.

\section{ETHICS STATEMENT}

The studies involving human participants were reviewed and approved by the Ethics Committee of the First Affiliated Hospital

\section{REFERENCES}

1. Eilertsen G, Ormstad H, Kirkevold M. Experiences of poststroke fatigue: qualitative meta-synthesis. J Adv Nurs. (2013) 69:51425. doi: $10.1111 /$ jan. 12002

2. Cumming TB, Packer M, Kramer SF, English C. The prevalence of fatigue after stroke: a systematic review and meta-analysis. Int J Stroke. (2016) 11:968-77. doi: 10.1177/1747493016669861

3. Winward C, Sackley C, Metha Z, Rothwell PM. A population-based study of the prevalence of fatigue after transient ischemic attack and minor stroke. Stroke. (2009) 40:757-61. doi: 10.1161/STROKEAHA.108.527101

4. Hartke RJ, Trierweiler R. Survey of survivors' perspective on return to work after stroke. Top Stroke Rehabil. (2015) 22:326-34. doi: 10.1179/1074935714Z.0000000044

5. Glader E-L, Stegmayr B, Asplund K. Poststroke fatigue: a 2year follow-up study of stroke patients in Sweden. Stroke. (2002) 33:1327-33. doi: 10.1161/01.STR.0000014248.28711.D6

6. Tralongo P, Respini D, Ferraù F. Fatigue and aging. Crit Rev Oncol Hematol. (2003) 48:S57-64. doi: 10.1016/j.critrevonc.2003.07.003

7. Schepers VP, Visser-Meily AM, Ketelaar M, Lindeman E. Poststroke fatigue: course and its relation to personal and stroke-related factors. Arch Phys Med Rehabil. (2006) 87:184-8. doi: 10.1016/j.apmr.2005.10.005

8. Skoie IM, Ternowitz T, Jonsson G, Norheim K, Omdal R. Fatigue in psoriasis: a phenomenon to be explored. Br J Dermatol. (2015) 172:1196203. doi: 10.1111/bjd.13647

9. Jones JM, Olson K, Catton P, Catton CN, Fleshner NE, Krzyzanowska $\mathrm{MK}$, et al. Cancer-related fatigue and associated disability in post-treatment cancer survivors. J Cancer Surviv. (2016) 10:51-61. doi: 10.1007/s11764-015-0 450-2

10. Mandliya A, Das A, Unnikrishnan JP, Amal MG, Sarma PS, Sylaja PN. Post-stroke fatigue is an independent predictor of post-stroke disability and burden of care: a path analysis study. Top Stroke Rehabil. (2016) 23:17. doi: 10.1080/10749357.2015.1110273

11. MacIntosh BJ, Edwards JD, Kang M, Cogo-Moreira H, Chen JL, Mochizuki $\mathrm{G}$, et al. Post-stroke fatigue and depressive symptoms are differentially related to mobility and cognitive performance. Front Aging Neurosci. (2017) 9:343. doi: 10.3389/fnagi.2017.00343 of Wenzhou Medical University. Written informed consent for participation was not required for this study in accordance with the national legislation and the institutional requirements.

\section{AUTHOR CONTRIBUTIONS}

$\mathrm{XY}, \mathrm{JH}$, and WR engaged in the study's conception and design. WR was responsible for the data statistics and paper writing. XY and $\mathrm{JH}$ reviewed the manuscript. All the following authors WR, JW, ZW, SY, XJ, MX, BW, and CX were responsible for collecting the data. All authors contributed to the article and approved the submitted version.

\section{FUNDING}

This work was supported in part by the National Key R\&D Programme of China (2018YFC1314200).

\section{ACKNOWLEDGMENTS}

The authors thank the patients of this study for their important contributions.

12. Carlsson GE, Möller A, Blomstrand C. Consequences of mild stroke in persons < 75 years - a 1-year follow-up. Cerebrovasc Dis. (2003) 16:3838. doi: $10.1159 / 000072561$

13. Choi-Kwon S, Han SW, Kwon SU, Kim JS. Poststroke fatigue: characteristics and related factors. Cerebrovasc Dis. (2005) 19:84-90. doi: 10.1159/000082784

14. Barritt AW, Smithard DG. Targeting fatigue in stroke patients. ISRN Neurol. (2011) 2011:805646. doi: 10.5402/2011/805646

15. Tang WK, Liang HJ, Chen YK, Chu WCW, Abrigo J, Mok VCT, et al. Poststroke fatigue is associated with caudate infarcts. J Neurol Sci. (2013) 324:131-5. doi: 10.1016/j.jns.2012.10.022

16. Tang WK, Liu XX, Chen YK, Abrigo J, Chu WCW, Mok VCT, et al. Cerebral microbleeds and fatigue in stroke. Eur Neurol. (2014) 71:2136. doi: $10.1159 / 000354845$

17. Wu D, Wang L, Teng W, Huang K, Shang X. Correlation of fatigue during the acute stage of stroke with serum uric acid and glucose levels, depression, and disability. Eur Neurol. (2014) 72:223-7. doi: 10.1159/0003 64902

18. Rieselbach RE. Renal handling of uric acid. Adv Exp Med Biol 76b. (1977) 76B:1-22. doi: 10.1007/978-1-4684-3285-5_1

19. Ames BN, Cathcart R, Schwiers E, Hochstein P. Uric acid provides an antioxidant defense in humans against oxidant- and radical-caused aging and cancer: a hypothesis. Proc Natl Acad Sci U S A. (1981) 78:685862. doi: 10.1073/pnas.78.11.6858

20. Davies KJ, Sevanian A, Muakkassah-Kelly SF, Hochstein P. Uric acid-iron ion complexes. a new aspect of the antioxidant functions of uric acid. Biochem J. (1986) 235:747-54. doi: 10.1042/bj2350747

21. So A, Thorens B. Uric acid transport and disease. J Clin Invest. (2010) 120:1791-9. doi: 10.1172/JCI42344

22. Auinger P, Kieburtz K, McDermott MP. The relationship between uric acid levels and Huntington's disease progression. Mov Disord. (2010) 25:2248. doi: $10.1002 / \mathrm{mds} .22907$

23. Winquist A, Steenland K, Shankar A. Higher serum uric acid associated with decreased Parkinson's disease prevalence in a large community-based survey. Mov Disord. (2010) 25:932-6. doi: 10.1002/mds.23070

24. Abraham A, Drory VE. Influence of serum uric acid levels on prognosis and survival in amyotrophic lateral sclerosis: a meta-analysis. J Neurol. (2014) 261:1133-8. doi: 10.1007/s00415-014-7331-x 
25. Moccia M, Lanzillo R, Palladino R, Russo C, Carotenuto A, Massarelli M, et al. Uric acid: a potential biomarker of multiple sclerosis and of its disability. Clin Chem Lab Med. (2015) 53:753-9. doi: 10.1515/cclm-2014-0744

26. Corry DB, Eslami P, Yamamoto K, Nyby MD, Makino H, Tuck ML. Uric acid stimulates vascular smooth muscle cell proliferation and oxidative stress via the vascular renin-angiotensin system. J Hypertens. (2008) 26:26975. doi: 10.1097/HJH.0b013e3282f240bf

27. Feig DI, Kang DH, Johnson RJ. Uric acid and cardiovascular risk. $N$ Engl J Med. (2008) 359:1811-21. doi: 10.1056/NEJMra0800885

28. Zhang H, Ma Y, Cao R, Wang G, Li S, Cao Y, et al. Soluble uric acid induces myocardial damage through activating the NLRP3 inflammasome. J Cell Mol Med. (2020) 24:8849-61. doi: 10.1111/jcmm.15523

29. Kutlubaev MA, Duncan FH, Mead GE. Biological correlates of poststroke fatigue: a systematic review. Acta Neurol Scand. (2012) 125:21927. doi: 10.1111/j.1600-0404.2011.01618.x

30. Wu S, Mead G, Macleod M, Chalder T. Model of understanding fatigue after stroke. Stroke. (2015) 46:893-8. doi: 10.1161/STROKEAHA.114.006647

31. Christensen D, Johnsen SP, Watt T, Harder I, Kirkevold M, Andersen G. Dimensions of post-stroke fatigue: a two-year follow-up study. Cerebrovasc Dis. (2008) 26:134-41. doi: 10.1159/000139660

32. Lerdal A, Lee KA, Bakken LN, Finset A, Kim HS. The course of fatigue during the first 18 months after first-ever stroke: a longitudinal study. Stroke Res Treat. (2012). 2012:126275. doi: 10.1155/2012/126275

33. De Doncker W, Dantzer R, Ormstad H, Kuppuswamy A. Mechanisms of poststroke fatigue. J Neurol Neurosurg Psychiatry. (2018) 89:28793. doi: 10.1136/jnnp-2017-316007

34. Kroenke K, Spitzer RL, Williams JB. The PHQ-9: validity of a brief depression severity measure. J Gen Intern Med. (2001) 16:606-13. doi: 10.1046/j.1525-1497.2001.016009606.x

35. Krupp LB, LaRocca NG, Muir-Nash J, Steinberg AD. The fatigue severity scale. Application to patients with multiple sclerosis and systemic lupus erythematosus. Arch Neurol. (1989) 46:1121-3. doi: 10.1001/archneur.1989.00520460115022

36. Zhang S, Liu L, Huang YQ, Lo K, Tang S, Feng YQ. The association between serum uric acid levels and ischemic stroke in essential hypertension patients. Postgrad Med. (2020) 132:551-8. doi: 10.1080/00325481.2020.1757924

37. Kamei K, Konta T, Hirayama A, Ichikawa K, Kubota I, Fujimoto S, et al. Associations between serum uric acid levels and the incidence of nonfatal stroke: a nationwide community-based cohort study. Clin Exp Nephrol. (2017) 21:497-503. doi: 10.1007/s10157-016-1311-7

38. Weir CJ, Muir SW, Walters MR, Lees KR. Serum urate as an independent predictor of poor outcome and future vascular events after acute stroke. Stroke. (2003) 34:1951-6. doi: 10.1161/01.STR.0000081983.34771.D2

39. Li M, Hou W, Zhang X, Hu L, Tang Z. Hyperuricemia and risk of stroke: a systematic review and meta-analysis of prospective studies. Atherosclerosis. (2014) 232:265-70. doi: 10.1016/j.atherosclerosis.2013.11.051

40. Li G, Miao J, Sun W, Song X, Lan Y, Zhao X, et al. Lower serum uric acid is associated with post-stroke depression at discharge. Front Psychiatry. (2020) 11:52. doi: 10.3389/fpsyt.2020.00052

41. Sun J, Lv X, Gao X, Chen Z, Wei D, Ling Y, et al. The association between serum uric acid level and the risk of cognitive impairment after ischemic stroke. Neurosci Lett. (2020) 734:135098. doi: 10.1016/j.neulet.2020.135098

42. Yuan K, Zhang X, Chen J, Li S, Yang D, Xie Y, et al. Uric acid level and risk of symptomatic intracranial haemorrhage in ischaemic stroke treated with endovascular treatment. Eur J Neurol. (2020) 27:104855. doi: 10.1111/ene.14202
43. Nozaki S, Tanaka M, Mizuno K, Ataka S, Mizuma H, Tahara T, et al. Mental and physical fatigue-related biochemical alterations. Nutrition. (2009) 25:517. doi: 10.1016/j.nut.2008.07.010

44. Lu Y, Yang R, Jiang X, Yang Y, Peng F, Yuan H. Serum metabolite profiles of postoperative fatigue syndrome in rat following partial hepatectomy. J Clin Biochem Nutr. (2016) 58:210-5. doi: 10.3164/jcbn.15-72

45. de Moffarts B, Kirschvink N, Art T, Pincemail J, Lekeux P. Effect of exercise on blood oxidant/antioxidant markers in standardbred horses: comparison between treadmill and race track tests. Equine Vet J Suppl. (2006) 36:2547. doi: 10.1111/j.2042-3306.2006.tb05548.x

46. Ruggiero C, Cherubini A, Ble A, Bos AJG, Maggio M, Dixit VD, et al. Uric acid and inflammatory markers. Eur Heart J. (2006) 27:117481. doi: 10.1093/eurheartj/ehi879

47. Gaab J, Rohleder N, Heitz V, Engert V, Schad T, Schürmeyer TH, et al. Stressinduced changes in LPS-induced pro-inflammatory cytokine production in chronic fatigue syndrome. Psychoneuroendocrinology. (2005) 30:18898. doi: 10.1016/j.psyneuen.2004.06.008

48. Collado-Hidalgo A, Bower JE, Ganz PA, Irwin MR, Cole SW. Cytokine gene polymorphisms and fatigue in breast cancer survivors: early findings. Brain Behav Immun. (2008) 22:1197-200. doi: 10.1016/j.bbi.2008.05.009

49. Miaskowski C, Dodd M, Lee K, West C, Paul SM, Cooper BA, et al. Preliminary evidence of an association between a functional interleukin6 polymorphism and fatigue and sleep disturbance in oncology patients and their family caregivers. J Pain Symptom Manage. (2010) 40:53144. doi: 10.1016/j.jpainsymman.2009.12.006

50. Zimmer P, Baumann FT, Oberste M, Schmitt J, Joisten N, Hartig P, et al. Influence of personalized exercise recommendations during rehabilitation on the sustainability of objectively measured physical activity levels, fatigue, and fatigue-related biomarkers in patients with breast cancer. Integr Cancer Ther. (2018) 17:306-11. doi: 10.1177/1534735417713301

51. McKechnie F, Lewis S, Mead G. A pilot observational study of the association between fatigue after stroke and C-reactive protein. J R Coll Physicians Edinb. (2010) 40:9-12. doi: 10.4997/JRCPE.2010.103

52. Ormstad H, Aass HC, Amthor KF, Lund-Sørensen N, Sandvik L. Serum cytokine and glucose levels as predictors of poststroke fatigue in acute ischemic stroke patients. J Neurol. (2011) 258:670-6. doi: 10.1007/s00415-011-5962-8

Conflict of Interest: The authors declare that the research was conducted in the absence of any commercial or financial relationships that could be construed as a potential conflict of interest.

Publisher's Note: All claims expressed in this article are solely those of the authors and do not necessarily represent those of their affiliated organizations, or those of the publisher, the editors and the reviewers. Any product that may be evaluated in this article, or claim that may be made by its manufacturer, is not guaranteed or endorsed by the publisher.

Copyright (C) 2022 Ren, $W u, W u$, Yang, Jiang, Xu, Wu, Xie, He and Yu. This is an open-access article distributed under the terms of the Creative Commons Attribution License (CC BY). The use, distribution or reproduction in other forums is permitted, provided the original author(s) and the copyright owner(s) are credited and that the original publication in this journal is cited, in accordance with accepted academic practice. No use, distribution or reproduction is permitted which does not comply with these terms. 